\title{
Analysis Study of The Effect in Selecting Combination of Fracturing Fluid Types and Proppant Sizes on Folds of Increase (FOI) To Improve Well Productivity
}

\author{
Dimas Ramadhan ${ }^{1 *}$, Hidayat Tulloh $^{2)}$ Cahyadi Julianto $^{3)}$ \\ 1) 2) 3) Petroleum Engineering Department, Faculty Of Mineral Technology, UPN Veteran Yogyakarta \\ * email korespondensi: dimasramadhanftm@gmail.com
}

\begin{abstract}
As fracturing materials, fracturing fluid and proppant are two very important parameters in doing hydraulic fracturing design. The combination of fracturing fluid and proppant selection is the main focus and determinant of success in the hydraulic fracturing process. The high viscosity of the fracturing fluid will make it easier for the proppant to enter to fill the fractured parts, so that the conductivity of the fractured well will be better and can increase the folds of increase (FOI) compared to fracturing fluid with lower viscosity. This research was conducted by using the sensitivity test method on the selection of fracturing fluid combinations carried out at the TX-01 well with various sizes of proppants (namely; 12/18, 16/20, and 20/40 mesh) with the proppant selected being ceramic proppant type carbolite performed using the FracCADE simulator. Fracturing fluid was selected based on its viscosity, namely YF240OD and PrimeFRAC20 fluids with viscosity value of $4.123 \mathrm{cp}$ and $171.1 \mathrm{cp}$, with a fixed pump rate of $14 \mathrm{bpm}$. The results showed that the combination of high-viscosity fluids (PrimeFRAC20) and 16/20 mesh proppant size resulted in a greater incremental fold (FOI) between the choice of another combination fracturing fluids and proppant sizes, namely 6.25 .
\end{abstract}

Keywords: folds of increase; fracturing fluids; hydraulic fracturing; proppant sizes; viscosity.

\section{INTRODUCTION}

Several factors that influence the success of hydraulic fracturing are the design of the fracturing fluid and proppant selection as the fracturing material treatment. Assessment of the success of Hydraulic Fracturing activities can be used the FOI (Fold of Increase) parameter namely the comparison of the well productivity index after and before hydraulic fracturing. The most important part in fracturing fluid is the viscosity parameter. The importance of viscosity in fracturing fluid is due to its ability to provide high conductivity results and to be able to transport proppants better than low-viscosity fluids, so fracturing fluids with high viscosity will provide a higher fold of increase (FOI) than lowviscosity fracturing fluids.

On the other hand, the development of proppants is also increasingly being carried out, starting with the type of sand, then RCS (resin coated sand) to ceramic proppants whose development is to be able to withstand higher closure pressure. Furthermore, the selection of the proppant size needs to be done, this cannot be separated from the combination of the fracturing fluid design selection which also affects the amount of the FOI value. The larger the proppant size, the greater the permeability obtained, so that the FOI value will be even greater. In fact, the small size of the proppant is able to enter into between smaller fractures completely so that it can more optimally propped at postfracturing.

The importance of choosing the fracturing material treatment is the focus in this study, so that it requires a sensitivity analysis on a combination of various types of fracturing fluid and proppant to be sensitive in order to choose which combination has the largest FOI value. Then the results are selected the combination that has the highest FOI value to be used as a reference in designing fracturing materials in the same hydraulic fracturing reservoir planning and / or with different reservoirs but having the same characteristics. So that the results of the sensitivity analysis data from the selection of the fracture and proppant fluid combination become a reference for planning the next hydraulic fracturing stimulation activity. The fracture of the reservoir rock, to be able to break it, has to give a pressure that exceeds the strength and forces that maintain the integrity of the rock. Some things that need to be considered in rock fracturing include rock mechanics, the design of the fracturing and proppant fluid planning, pumping planning, to the implementation of fracturing. Following are some of the rock mechanics parameters used in hydraulic fracturing activities:

- Stress

Stress $(\sigma)$ is defined as the force acting on an area. Mathematically, stress can be written as:

Explanation:

$$
\sigma \Delta=\lim _{A \rightarrow 0}\left(\frac{\Delta F}{\Delta A}\right)
$$


$\sigma=$ Stress, Psi.

$\mathrm{F}=$ Working force, $\mathrm{lb}$.

$\mathrm{A}=$ Area, inch2

The main stress magnitudes on rocks consist of overburden stress / vertical stress, maximum horizontal stress, and minimum horizontal stress.

The price of vertical stress / overburden pressure can be estimated, namely:

$$
\begin{aligned}
& \sigma_{v}=g \int_{0}^{H} \rho(H) d H \\
& \text { or } \\
& \sigma_{v}=\frac{\rho H}{144}
\end{aligned}
$$

Explanation:

$\sigma_{-} \mathrm{v}=$ Overburden pressure, $\mathrm{psi}$.

$\mathrm{g}=$ Gravity $\mathrm{lb} / \mathrm{ft} 2$.

$\rho=$ Density of rock, $\mathrm{lb} / \mathrm{ft} 3$.

$\mathrm{H}=$ Depth, ft.

Meanwhile, to calculate the effective vertical stress, the amount of overburden pressure or absolute vertical stress must be reduced by multiplying the poroelastic biot constant.

$$
\sigma^{\prime} v=\sigma v-\alpha p
$$

Explanation :

$\sigma_{v}^{\prime}=$ Effective vertical stress, psi.

$\sigma_{v}=$ Vertical stress, psi.

$\rho=$ Rock density, $\mathrm{lb} / \mathrm{ft} 3$.

This effective vertical stress can be translated into a horizontal direction with the Poisson Ratio as follows:

$$
\sigma_{H}^{\prime}=\frac{v}{1-v} \sigma_{v}
$$

The minimum effective stress rates is :

$$
\sigma_{H \min }=\sigma_{H}^{\prime}
$$

And the absolute minimum stress value can be written mathematically:

$$
\sigma_{H \min }=\sigma_{H}^{\prime}+\alpha P
$$

To get the absolute maximum horizontal stress value, it is necessary to add a tectonic effect (Guo, 2006). Mathematically it can be written

$$
\sigma_{H \max }=\sigma_{H \min }+\sigma_{\text {tect }}
$$

\section{- Pressure Fracture}

In the hydraulic fracturing process, to be able to fracture the reservoir rock, a pressure is needed to fight or overcome the forces that maintain the integrity of the rock 'Pbd' (breakdown pressure), written

$$
\mathrm{Pbd}=3 \sigma_{\mathrm{Hmin}}-\sigma_{\mathrm{Hmax}}+\mathrm{T}_{0}-\mathrm{Pp}
$$

Explanation :

Pbd $=$ Breakdown pressure, psia.

$\sigma_{\mathrm{Hmin}}=$ Minimum horizontal stress absolute, psia

$\sigma_{\text {Hmax }}=$ Maximum horizontal stress absolute, psia.

$\mathrm{T}_{0} \quad=$ Tensile Strength rock, psia.

$\mathrm{Pp} \quad=$ Rock pore pressure, psia.

In simple terms, to find the value of the fracture pressure at the bottom of the well, you can also write it by:

$$
\mathrm{P}_{\mathrm{bd}}=\mathrm{BHTP}=\text { gf } \mathrm{x} \text { Dperfo }
$$


Then to calculate how much total injection pressure is needed on the surface it can be written by:

$$
\text { Pip }=\text { WHTP }=P_{b d}+P_{f}+P_{p p f}-P_{h}+\text { Pnet }
$$

Explanation :

Pip = Surface injection pressure, psia. Pbd = Rock fracture pressure, psia.

BHTP $=$ Bottom-Hole Treating Pressure, psia.

Pf $=$ Loss of pressure in the pipe (tubing), psi.

Pppf $=$ Loss of pressure in the perforation. psi

$\mathrm{Ph}=$ Hydrostatic pressure of fracturing fluid, psia.

\section{- Fracturing Fluids}

In 1949, J.B. Clark publishes about fracturing fluid in "Hydrafac" in the process of increasing well productivity, which needs to include several requirements for the properties of the fluid including:

1. The viscosity possessed is sufficient to make fractures and transport proppants.

2. Compatibility between fracturing fluid and formation in order to minimize formation damage

3. Reduction in fluid viscosity after proppant is placed in formation to maximize conductivity.

Fracturing fluids with high viscosity assisted by high pressure will generally provide large fractures (Figure 1). In limited vertical fractures, fluid loss control tends to provide additional support to the fracture width.

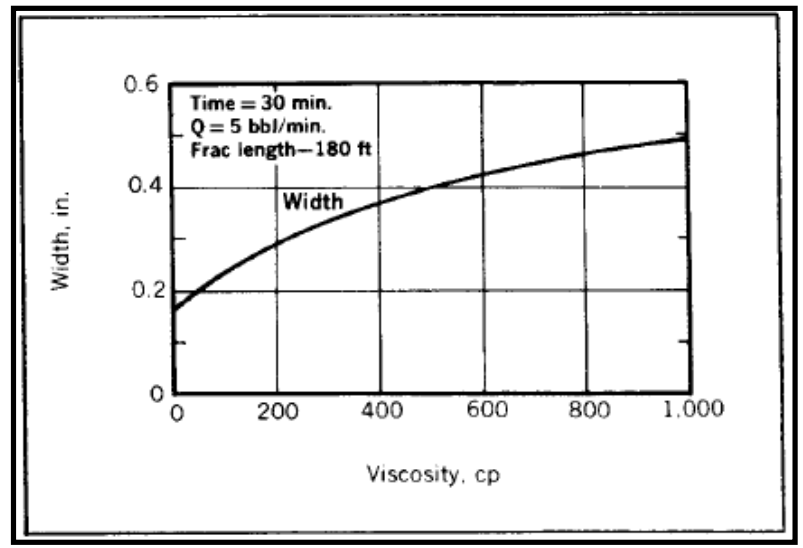

Figure 1. The relationship between viscosity and fracture width

Source : Allen, T.O., Robert, A.P., 1982

(Economides,2000) provides guidance regarding the selection of fracturing fluids based on formation temperature, sensitivity to water, permeability, reservoir pressure and fracture height. (Figure 2) provides directions for selecting fracturing fluid for oil wells.

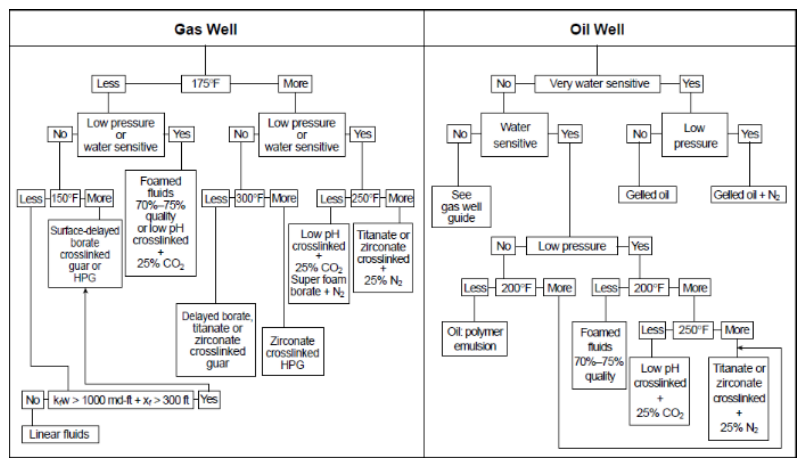

Figure 2. Guidelines for Selection of Fracturing Fluid

Source: Economides, et.al., 2000 
The main purpose of placing proppants in the fracture is to prevent the formed fracture from closing again after pumping has stopped. In hydraulic fracturing, the desired proppant is uniformly dense with maximum conductivity, otherwise evenly distributed throughout the fracture. A good proppant and in accordance with the characteristics of the formation will be able to maintain high fracture conductivity. Mathematically, the fracture conductivity can be written as follows:

$$
\mathrm{Wkf}=\mathrm{kf} \mathrm{W}
$$

Information :

$\mathrm{Wkf}=$ fracture conductivity, $\mathrm{mD}-\mathrm{ft}$.

$\mathrm{kf}=$ fracture permeability, $\mathrm{mD}$.

$\mathrm{w}=$ Width of fracture, $\mathrm{ft}$.

The larger proppant provides higher fracture conductivity due to the larger pore space in the proppant package. The use of a large proppant size is easily damaged or destroyed. This is due to the lack of contact area / surface of the proppant that can withstand the pressure distribution. A wider range of proppant particle sizes results in tighter packaging arrangements as well as lower permeability/conductivity.

\section{- Geometry Fracture Model}

There are three types of 2D fracture models, namely, radial, Perkins-Kern-Nordgren (PKN) and Klerk fracture (KGD) models.

\section{a. The Perkins-Kern-Nordgren (PKN) model}

This method is used when the length (or deep) of the fracture is much greater than the height of the fracture (xf $>>\mathrm{hf}$ ). This model assumes that the fracture height is constant and limited, each end of the fracture is tapered, the maximum fracture width occurs in the middle of the fracture section, while the minimum width occurs at the end of the fracture section so that there will be variations in the width of the fracture from the borehole to the lateral end.

The model is based on the assumption that:

1. The length of the fracture / fracture penetration is much greater than the height of the fracture $(\mathrm{xf}>>\mathrm{hf})$.

2. The height of the fracture is equal to the thickness of the reservoir.

3. The pressure is considered constant in the direction of the vertical slice, the stiffness of the rock reacts vertically.

\section{b. KGD models (Kristianovich, Geertsma and De Klerk)}

The KGD model is the result of a rotation of 90o from the PKN model. The KGD model is the same width (like a rectangle) along the fracture and is half elliptical at the end. The KGD model has relatively shorter, wider fractures with greater conductivity than the PKN model.

\section{c. Combination of Non-Newtonian Effects and Fluid Loss}

Peter Valko and Economides provide solutions for PKN and KGD with a combination of effects both for non Newtonian and the presence of fluid loss (laminar). The reduction uses apparent viscosity for non Newtonian fluids for both PKN and KGD. The results are as follows:

$$
\begin{aligned}
& x_{f}=\frac{\left(\bar{w}+2 S_{p}\right) q_{o}}{4 C_{1}{ }^{2} \pi h_{f}}\left[\exp \left(\beta^{2}\right) \operatorname{erfc}(\beta)+\frac{2 \beta}{\sqrt{\pi}}-1\right] \\
& \beta=\frac{2 C_{L} \sqrt{\pi t}}{\bar{w}+2 S_{p}}
\end{aligned}
$$

PKN Model

$$
w_{(0)}=9,15^{\frac{1}{2 n^{\prime}+2}} \times 3,98^{\frac{n^{\prime}}{2 n^{\prime}+2}}\left[\frac{1+2,14 n^{\prime}}{n^{\prime}}\right]^{\frac{n^{\prime}}{2 n^{\prime}+2}} \times K^{\prime} \frac{1}{2 n^{\prime}+2}\left[\frac{q_{i}^{n \prime} h_{f}^{\left(1-n^{\prime}\right)} x_{f}}{E^{\prime}}\right]^{\frac{1}{2 n^{\prime}+2}}
$$

Assuming that its shape factor

$$
\begin{aligned}
& \bar{w}=(\pi / 5) \mathrm{w}(0) \text { and, } \\
& P_{\text {net }}=\Delta P f=E^{\prime}(w(0)) /\left(2 h_{f}\right)
\end{aligned}
$$




\section{KGD Model}

$$
w_{(0)}=11,1 \frac{1}{2 n^{\prime}+2} x 3,24 \frac{n^{\prime}}{2 n^{\prime}+2}\left[\frac{1+2 n^{\prime}}{n^{\prime}}\right]^{\frac{n^{\prime}}{2 n^{\prime}+2}} \times K^{\prime} \frac{1}{2 n^{\prime}+2}\left[\frac{q_{i}{ }^{\prime \prime} x_{f}{ }^{2}}{h_{f}{ }^{n \prime} E^{\prime}}\right]^{\frac{1}{2 n^{\prime}+2}}
$$

The $\mathrm{xf}$ price is obtained as in the PKN above and

$$
\begin{aligned}
& \bar{w}=(\pi / 4) w(0) \text { and }, \\
& P_{n e t}=\Delta P_{f}=E^{\prime}(w(0)) /\left(4 x_{f}\right)
\end{aligned}
$$

Explanation :

E '= Plane Strain Modulus

$\mathrm{E}^{\prime}=\mathrm{E} /\left(1-\mathrm{v}^{\wedge} 2\right)$

$\mathrm{Sp}=$ spurt loss, $\mathrm{m}$ (meters)

qo $=$ injection rate in $\mathrm{m} 3 / \mathrm{s}$

$\mathrm{Ct}=$ fluid loss coefficient, $\mathrm{m} / \mathrm{s} 1 / 2$

$\mathrm{hf}=$ fracture height, $\mathrm{m}$

$\mathrm{t}=$ time, seconds

$\mathrm{W}(0)=$ width of the fracture in the well

$\mathrm{w}=$ average fracture width, $\mathrm{m}$

$\mathrm{xf}=\mathrm{L}=$ fracture length of one wing, $\mathrm{m}$

\section{METHODS}

\section{Data Collection}

Data collection was carried out before planning hydraulic fracturing at the Well TX-01 of "DHC" field including rock mechanics data, reservoir data, well completion data, perforation data, fracturing fluid data and proppant data. These data are collected from existing data or through various considerations and observations of data obtained from previous hydraulic fracturing implementation. The design of hydraulic fracturing at the Well TX-01 of "DHC" field was carried out using FracCADE software.

\section{Preparation of Hydraulic Fracturing Operation}

Before carrying out the hydraulic fracturing work, some planning and preparation was carried out starting from data collection, selecting the fracturing fluid and proppant to be used, to making the initial design.

\section{Pre-Frac Test}

Before carrying out the main hydraulic fracturing, a series of tests is carried out to obtain data from below the surface and can also provide an overview of the fracture results that will later be formed. The pre-frac test data that has been carried out on the Well TX-01 are the Step-rate Test data and the Mini Frac Test data. The step-rate test was conducted to find the value of clossure stress and fracture extension pressure (Montgomery, 2015). Meanwhile, the purpose of the mini frac type pre-frac test is to find out accurate information on the formation target to be broken. The mini frac in the Well TX-01 was carried out without using a proppant.

\section{Planning for Selection of Fracture Fluid}

The fracture fluid used in this planning has two types based on the difference in viscosity. The selection of fracturing fluid variations based on the difference in viscosity is respectively $4.123 \mathrm{cp}$ and $117.1 \mathrm{cp}$, namely waterbased fracturing fluid added with gelling agent and cross-linker to increase viscosity. Besides that, it can withstand high temperatures and also several other additives such as clay stabilizer in the form of methanol and $\mathrm{KCl}$ which functions to avoid the active response of the clay content in the formation. Then the addition of the fluid loss additive so that the amount of fluid lost can be minimized as well as the addition of buffers and breakers to maintain $\mathrm{pH}$ and to break the polymer chain so that it becomes dilute again (small in viscosity) after placing the proppant so that the production of oil flow becomes smooth. 


\section{Proppant Selection Planning}

The choice of proppant or wedge material is based on the ability to hold the fracture open (withstand clossure stress) as well as the desired conductivity. In the Well TX-01, three types of proppant sizes were selected, namely 12/18, 16/20, and 20/40 mesh, the Carbolite type is the Ceramic type which will be sensitive to the folds of increase value. This type and size proppant was chosen because it provides good resistance to the crushed effect of clossure pressure. In addition, this type of proppant has a good roundness and sphericity size of 0.9 so it can withstand stress in the formation.

\section{FracCADE Simulation}

The fracture fluid and proppant size selected for analysis of the effect on FOI were YF240OD and PrimeFRAC20 with a viscosity of $4.123 \mathrm{cp}$ and $117.1 \mathrm{cp}$, while for proppant, a Carbolite type of ceramic proppant was selected with the proppant size sensitivity being 12/18, 16/20, and the 20/40 mesh shown in Table 2.

Table 2. Scenario of Fracture Fluid and Proppant Selections

\begin{tabular}{|c|c|}
\hline Fracture Fluid & Proppant Size, Mesh \\
\hline \multirow{3}{*}{ YF240OD } & $12 / 18$ Carbolite \\
\cline { 2 - 2 } & $16 / 20$ Carbolite \\
\cline { 2 - 2 } & $20 / 40$ Carbolite \\
\hline \multirow{3}{*}{ PrimeFRAC20 } & $12 / 18$ Carbolite \\
\cline { 2 - 2 } & $16 / 20$ Carbolite \\
\cline { 2 - 2 } & $20 / 40$ Carbolite \\
\hline
\end{tabular}

After obtaining the fracture results from the simulation, such as fracture length (Xf), fracture width (w (o)), fracture height (Hf), and effective conductivity (wkf) from various combinations of fracture fluid selection and proppant size. Next, calculate the FOI value (fold of increase). FOI calculations were performed using the McGuire \& Sikora, Cinco-Ley Samaniego and Tinsley \& Soliman methods for each simulation treatment carried out with the sensitivity of various combinations of fluid types and proppant sizes.

\section{RESULTS AND DISCUSSION}

Based on the results of calculations and simulations using the PKN 2D method with FracCADE software, the fracture geometry to FOI were obtained from each of the fracturing fluid selection sensitivity and proppant size as follows:

- YF240OD fluid (4.123 cp) combined with 12/18 mesh produces a fracture length (Xf) of $435.5 \mathrm{ft}$, fracture height (hf) of $15.7 \mathrm{ft}$, fracture width (w) of 0.5533 inch, and conductivity (wkf) ) of $822 \mathrm{md} . \mathrm{ft}$.

- YF240OD fluid $(4.123 \mathrm{cp}$ ) combined with $16 / 20$ mesh produces a fracture length $(\mathrm{Xf})$ of $435.5 \mathrm{ft}$, fracture height (hf) of $15.7 \mathrm{ft}$, fracture width (w) of 0.5533 inch, and conductivity (wkf) ) of 2957 md.ft.

- YF240OD fluid (4,123 cp) combined with 20/40 mesh produces a fracture length (Xf) of $435.5 \mathrm{ft}$, fracture height (hf) of $15.7 \mathrm{ft}$, fracture width (w) of 0.5533 inch, and conductivity (wkf) ) of $2407 \mathrm{md} . \mathrm{ft}$.

- PrimeFRAC20 fluid $(117.1 \mathrm{cp})$ combined with 12/18 mesh produces a fracture length (Xf) of $322.7 \mathrm{ft}$, fracture height (hf) of $15.7 \mathrm{ft}$, fracture width (w) of 0.8101 inch, and conductivity (wkf) of 1367.9 md.ft.

- PrimeFRAC20 fluid $(117.1 \mathrm{cp})$ combined with 16/20 mesh produces a fracture length $(\mathrm{Xf})$ of $322.7 \mathrm{ft}$, fracture height (hf) of $15.7 \mathrm{ft}$, fracture width (w) of 0.8101 inch, and conductivity (wkf) of $3805 \mathrm{md} . \mathrm{ft}$.

- PrimeFRAC20 fluid (117.1 cp) combined with 20/40 mesh results in fracture length (Xf) of $322.7 \mathrm{ft}$, fracture height (hf) of $15.7 \mathrm{ft}$, fracture width (w) of 0.8101 inch, and conductivity (wkf) of $3097 \mathrm{md} . \mathrm{ft}$.

Then the calculation of the comparison of the productivity index after hydraulic fracturing (FOI) using the McGuire \& Sikora method, Cinco ley-Samaniego method, and the Tinsley \& Soliman method. The results of calculations using the McGuire \& Sikora method (Figure 3 (a)) are 2.06, 3.38, and 3.21 for the viscosity fluid of $4.123 \mathrm{cp}$ with mesh sizes are $12 / 18,16 / 20$ and 20/40, the FOI value are $2.49,4.5$ and 3.42 for the viscosity fluid of $117.1 \mathrm{cp}$ with mesh sizes are 12/18, 16/20 and 20/40. The results of calculations using the Cinco ley-Samaniego method (Figure 3 (b)) are 4.02, 5.77, and 4.86 for the viscosity fluid of $4.123 \mathrm{cp}$ with mesh sizes are 12/18, 16/20 and 20/40, and FOI value of 4.09, 6.25 and 5.18 for the viscosity fluid of $117.1 \mathrm{cp}$ with mesh sizes are 12/18, 16/20 and 20/40. The results of calculations using the Tinsley \& Soliman method (Figure 3 (c)) are 2.27, 3.59, and 2.49 for the viscosity fluid of $4.123 \mathrm{cp}$ mesh sizes are $12 / 18,16 / 20$ and 20/40, the FOI value are $2.35,3.77$ and 2.62 for the viscosity fluid of $117.1 \mathrm{cp}$ with mesh sizes are 12/18, 16/20 and 20/40. The results of the calculation of the FOI value are shown in Table 3 below. 
Table 3. Calculation Results of Folds of Increase

\begin{tabular}{|c|c|c|c|c|}
\hline Fluid Types & $\begin{array}{c}\text { Proppant } \\
\text { Size, } \\
\text { Mesh }\end{array}$ & $\begin{array}{c}\text { McGuire \& } \\
\text { Sikora } \\
\text { Method }\end{array}$ & $\begin{array}{c}\text { Metode Cinco } \\
\text { ley-Samaniego } \\
\text { Method }\end{array}$ & $\begin{array}{c}\text { Metode Tinsley \& } \\
\text { Soliman Method }\end{array}$ \\
\hline \multirow{4}{*}{ YF240OD } & $12 / 18$ & 2.06 & 4.02 & 2.27 \\
\cline { 2 - 5 } & $16 / 20$ & 3.38 & 5.77 & 3.59 \\
\cline { 2 - 5 } & $20 / 40$ & 3.21 & 4.86 & 2.49 \\
\hline \multirow{3}{*}{$\begin{array}{c}\text { PrimeFRAC } \\
20\end{array}$} & $12 / 18$ & 2.49 & 4.09 & 2.35 \\
\cline { 2 - 5 } & $16 / 20$ & 4.5 & 6.25 & 3.77 \\
\cline { 2 - 5 } & $20 / 40$ & 3.42 & 5.18 & 2.62 \\
\hline
\end{tabular}

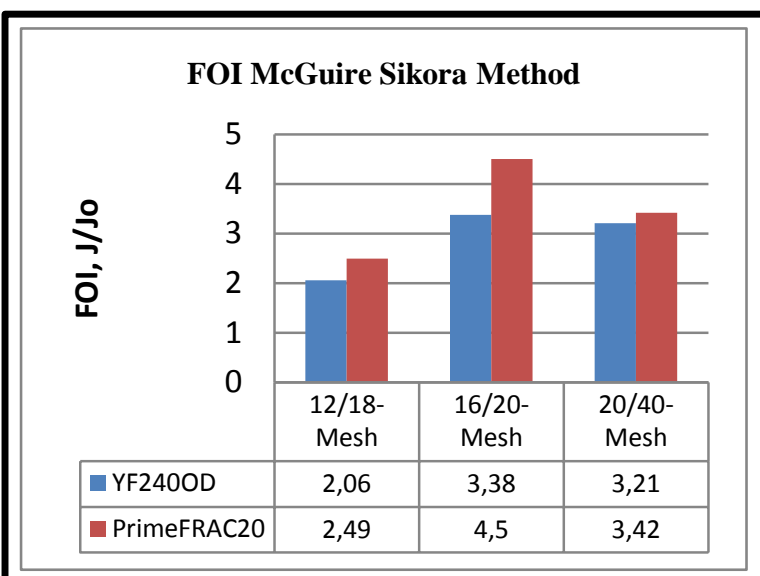

(a)

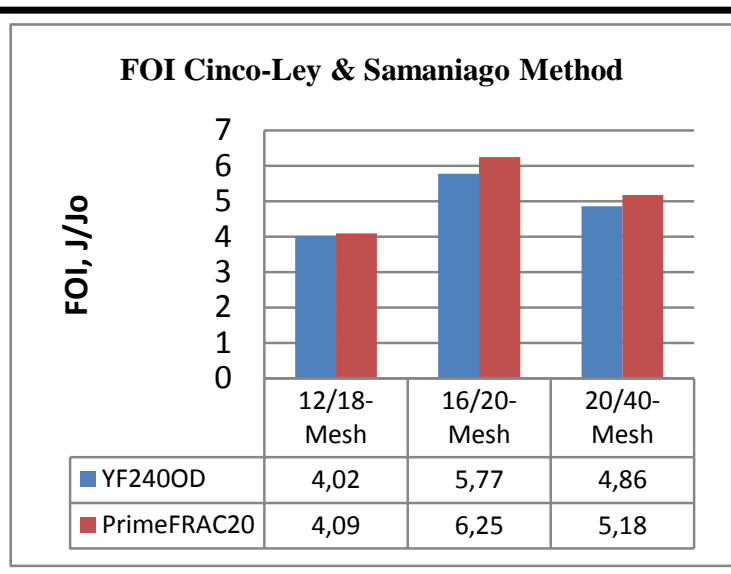

(b)

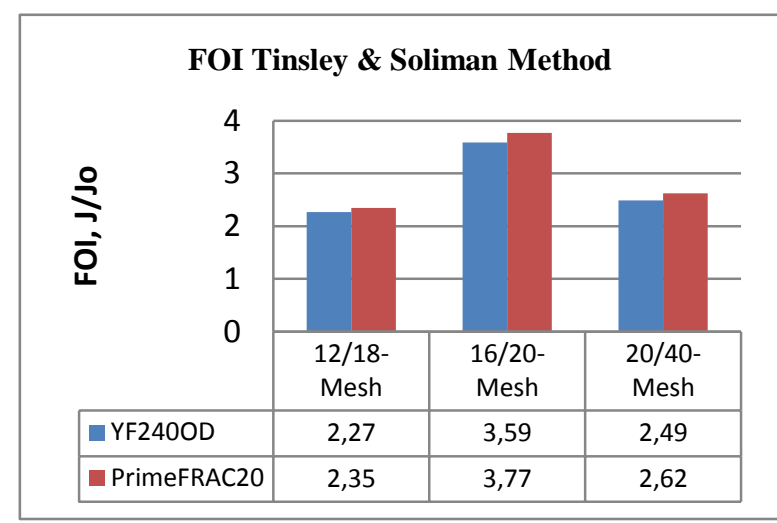

(c)

Figure 3 (a). FOI Graph of the Mc Guire \& Sikora Method on Well TX-01, Figure 3 (b). FOI Graph of the Cinco-Ley \& Samaniago Method on Well TX-01, and Figure 3 (c). FOI Graph of the Tinsley \& Soliman Method on Well TX-01

Based on the overall analysis of the calculation results of the FOI, the largest FOI value is 6.25 , which is the combination of the choice of fracturing fluid for the type of PrimeFRAC20 with a viscosity of $117 \mathrm{cp}$ with a proppant size of 16/20 mesh. The combination of fluid selection has a fracture length of $416.5 \mathrm{ft}$ with a fracture width of 0.4855 
inch and produces a high fracture conductivity of 5167 md.ft. Thus it is recommended that hydraulic fracturing in the TX-01 well be carried out with a high viscosity fracture fluid such as PrimeFRAC20 fluid which has a viscosity of $117.1 \mathrm{cp}$, then for proppant selection, a proppant with a small mesh size should be selected to form high conductivity so that can increase productivity with optimal hydraulic fracturing design.

The results of the analysis of the effect of selecting the combination of fracturing fluid and proppant size on the amount of FOI indicate that the use of PrimeFRAC20 fluid has a higher viscosity value than YF240OD fluid, this is because the viscosity of PrimeFRAC fluid is higher than YF240OD fluid, so it can provide fracture width and fracture conductivity large because it can transport proppants better than fluids with low viscosity. Likewise with the proppant size, the larger the proppant size (the smaller the proppant mesh value), the greater the conductivity that can be formed after fracturing. In the picture above there is an error for the proppant size 16/18 mesh, this proppant should have a higher conductivity than other proppant sizes, but the conductivity value at 16/18 mesh size in this study is smaller than the others, this is due to its physical properties provided by FracCADE Software.

\section{CONCLUSION}

Based on the studies that have been carried out in conducting analysis studies on the selection of the combination of fracturing fluid and the sizes of the proppants to the value of folds of increase (FOI) in the TX-01 well of "DHC" field, the following conclusions were obtained:

1. PrimeFRAC20 fluid has a greater FOI value than YF240OD fluid, it's because the viscosity of PrimeFRAC fluid is higher than YF240OD fluid, so it can provide greater fracture width and conductivity because it can transport proppants better than fluids with low viscosity.

2. The larger the proppant size (the smaller the proppant mesh value), the greater the conductivity that can form after fracturing.

3. The TX-01 well produced the highest FOI value of 6.25 using a combination of the choice of a fracturing fluid PrimeFRAC20 with a viscosity of $117.1 \mathrm{cp}$ with a proppant size $16 / 20$ mesh C-Lite, so it is recommended for further fracturing in the same reservoir conditions and layers can be to increase the productivity of the well.

4. It is necessary to do further research related to the FOI value for each sensitivity to permeability so that it is expected to increase the productivity of well production.

\section{REFERENCES}

Allen, Thomas., Roberts, Allan P.,1989, “Production Operations Volume 2”, Oil and Gas International Consultants, Oklahoma.

Carl T. Montgomery \& Michael Berry Smith, 2015, “Hydraulic Fracturing” CRC Press, Boca Raton.

Economides, J. Michael., Hill, Daniel A.,1994, "Petroleum Production System”, Prentice Hall PTR, New Jersey.

Economides, J. Michael., Nolte., K.G.,2000, "Reservoir Stimulation 3rd Edition”, Schlumberger Educational Services, Houston, Texas.

Economides, J. Michael.,2007, “Modern Fracturing Enhancing Natural Gas Production”, BJ Services Company, Houston, Texas.

Feng Liang \& Mohammed Sayed, 2015, “Overview of Existing Proppant Technologies and Challenges" SPE 172763MS.

Fred Aminzadeh, 2019, "Hydraulic Fracturing and Well Stimulation”, Scrivener Publishing LLC, River Street, Hoboken.

Guo, Buyon dkk,2017, "Petroleum Production Engineering”, Professional Publishing, Oxford.

Hoss Belyadi, Ebrahim Fathi, Fathemeh Belyadi, 2017, "Hydraulic Fracturing in Unconventional Reservoirs: Theories, Operations, and Economic Analysis" Gulf Professional Publishing, Kidlington, Oxford.

Jack R. Jones and Larry K. Britt.,2009, "Design and Appraisal of Hydraulic Fracturing, Society of Petroleum Engineers, United States

Miskimins Jennifer, 2019, "Hydraulic Fracturing: Fundamentals and Advancements, Society of Petroleum Engineers, Texas.

Suwardi,2009, "Evaluasi Hydraulic Fracturing dalam Rangka Peningkatan Produktivitas Formasi”, Jurnal Ilmu Kebumian Teknologi Mineral Vol. 22, Universitas Pembangunan Nasional Veteran Yogyakarta.

V. P. P. de Campos, E. C. Sansone, and G. F. B. L. e Silva, 2018, "Hydraulic Fracturing Proppants" Cerâmica, 219229. 